Journal of Educational

and Psychological Sciences

Volume (5), Issue (51): 30 Dec 2021

P: 110 - 123

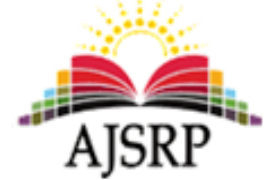

ISSN: 2522-3399

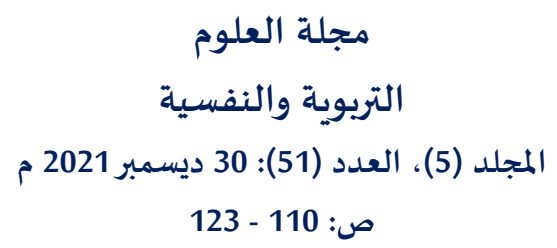

مجلة العلوم

التربوية والنفسية

ص: 110 - 123

\title{
The degree to which Islamic education teachers in the northeastern Badia possess technological knowledge in light of the standards of total quality management
}

\author{
Fayez Sobh Arab Aoun \\ Ministry of Education || Jordan
}

\begin{abstract}
The study aimed to identify the acquisition degree of technological knowledge by Islamic education teachers in light of the total quality management (TQM) standards in the North-Eastern Badia.To achieve the objectives of the study, the researcher prepared and distributed a questionnaire to (212) male and female teachers in the schools of the directorate of education of the North-eastern Badia After conducting the statistical analysis, it was evident that the degree of possessing the technological knowledge was medium, there were statistically significant differences at the level of significance ( $\alpha \leq$ 0.05) between the average responses and the members of the study sample regarding the acquisition degree of technological knowledge by the Islamic education teachers in light of the TQM standards according to the variable of gender in favor of females, no statistically significant differences at the level of significance $(0.05 \leq \alpha)$ between the average responses and the members of the study sample regarding the acquisition degree of technological knowledge by the Islamic education teachers in light of the TQM standards according to the scientific qualification variable, and statistically significant differences at the level of $(0.05 \leq \alpha)$ between the average responses and the members of the study sample regarding the acquisition degree of technological knowledge by the Islamic education teachers in light of the TQM standards according to the variable of experience in favor of the number of years of experience (less than five years).
\end{abstract}

Keywords: Islamic education - technological knowledge - total quality management - the northeastern Badia.

$$
\begin{aligned}
& \text { درجـة امتلاك مُدربي التربية الإسـلامية في البادية الشمالية الشـرقية للمعرفة } \\
& \text { التكنولوجية في ضوء معايير إدارة الجودة الشـاملة } \\
& \text { فايز صببح عرب العون } \\
& \text { وزارة التربية والتعليم || الأردن }
\end{aligned}
$$

المستخلص: هدفت هذه الدراسة للتعرف على درجة امتلاك مُدرسي التربية الإسلامية في البادية الشمالية الشرقية، للمعرفة التكنولوجية في ضوء معايير إدارة الجودة الشاملة ولتحقق أهداف الدراسة قام الباحث بإعداد استبانة وتوزيعها على عينة من (212)

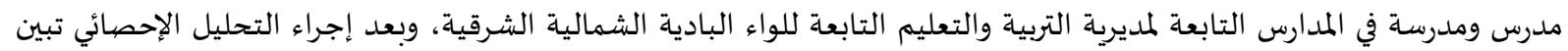

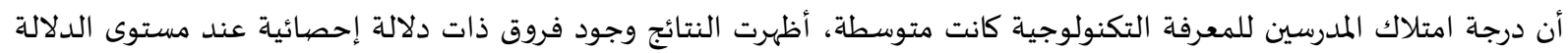

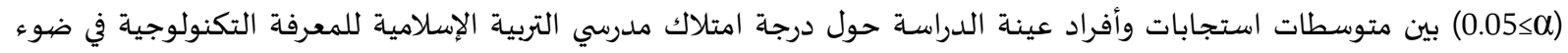

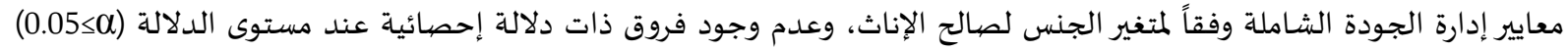

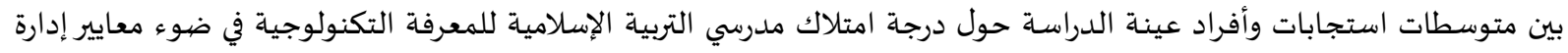

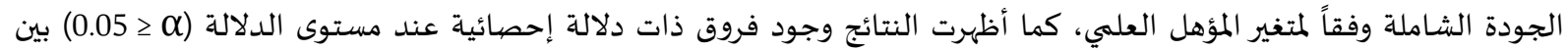


متوسطات استجابات وأفراد عينة الدراسة حول درجة امتلاك مدرسي التربية الإسلامية للمعرفة التكنولوجية في ضوء معايير إدارة

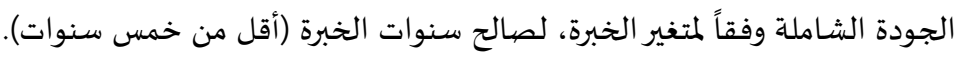
الكلمات المفتاحية: التربية الإسلامية - المعرفة التكنولوجية - إدارة الجودة الشاملة - البادية الشمالية الشرقية.

المقدمة.

إن إصلاح التعليم يمر عبر العديد من القنوات في جميع انحاء العالم فمن هذه القنوات ما يتجها إلى العمل

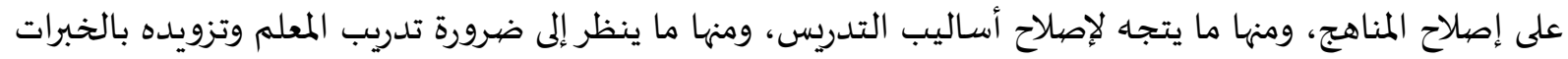

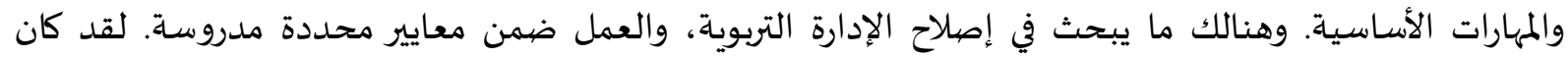

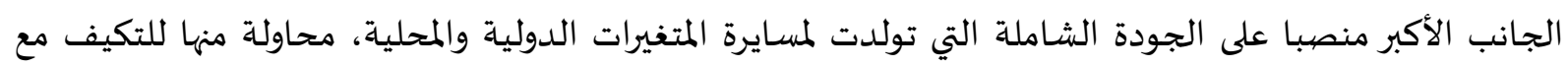

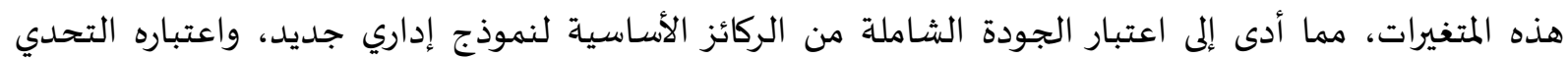

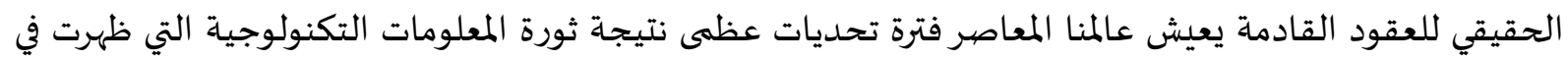

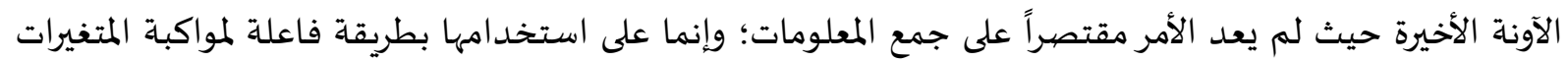
الاقتصيادية والاجتماعية.

وتحتل التربية الإسلامية مكانة كبيرة كونها تستمد أهدافها ومحتواها وأساليهها وكل ما يتعلق ببنائها وأصهولها

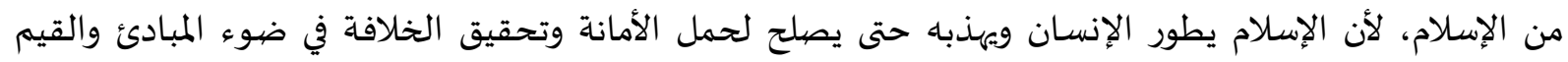

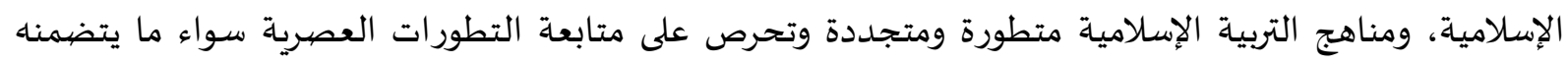

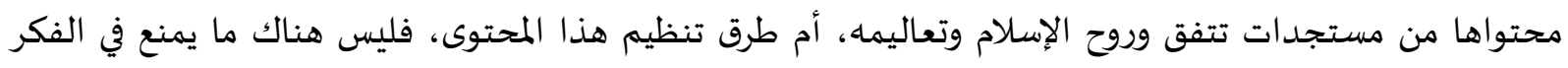
التربوي الإسلامي من تطبيق أي نمط من أنماط تنظيم خبرات المنهج ومحتوياته، إذا أثبتت التجربة العلمية أفضيليته على غيره من من الأنماط (حماد، 2011).

ولقد حظيت الجودة باهتمام كبير في معظم دول العالم، باعتبارها إحدى الدعامات الأساسية لأنظمة التعليم التي ينبغي عليها مواكبة التغيرات العالمية والتكيف معها، ونقطة انطلاق الكوادر البشرية المؤهلة علمياً،

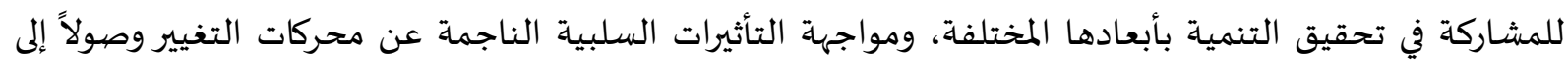
حلول عملية تعود بالفائدة على المجتمعات، ولتحقيق ذلك فإن عملية ضمان الجودة تعمل على تطبيق أساليب متقدمة، لتحسين مستوى التعليم وتفعيل الممارسات الموجودة وتطويرها باستمرار، وتحقيق أعلى المستويات الممكنات

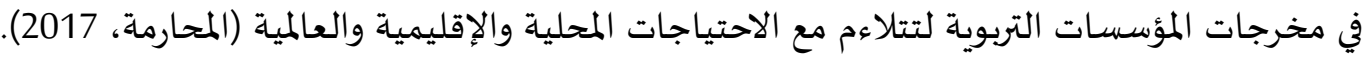
والجودة الشاملة هي فلسفة إدارية لقيادات الجامعة تركز على إشباع حاجات الطلاب والمستفيدين، وتحقق نمو الجامعاة، وتوصلها إلى أهدافها، وهي تضمن الفاعلية العظمى، والكفاية المرتفعة في الحقل العلمي والبحثي التي تؤدي في الهاية إلى التفوق والتميز، وتشمل الجودة الجامعية جميع الكليات والإدارات والعاملين (أبو صاع، 2019)،

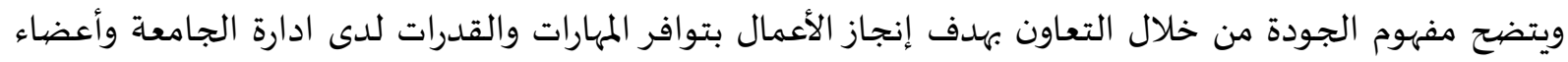

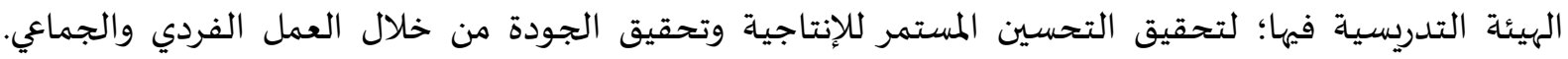
وتشير المراجع إلى تعدد مفاهيم مفردة الجودة، حيث تفسّر وفق صياغ استخدامها، إذ تعرف المنظمة الدولية للقياس

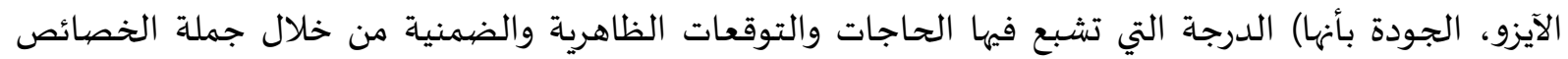

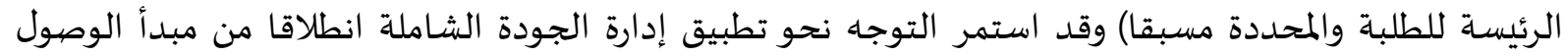
للتفوق على رغبات المجتمع (عبد الرحيم، 2010). 
وعليه أصبحت الجودة من الأولويات العليا لأي منظمة تسعى للحصول على ميزة تنافسية تمكنها من البقاء

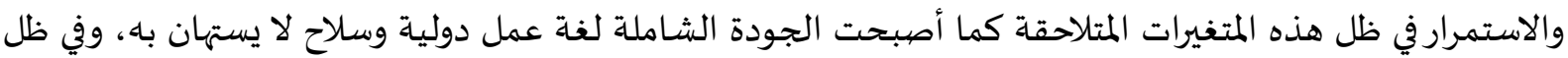

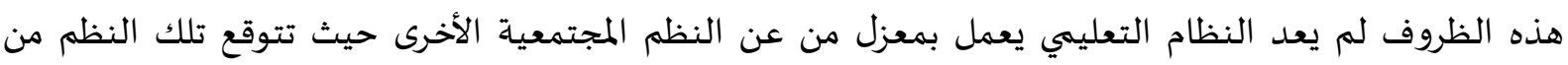

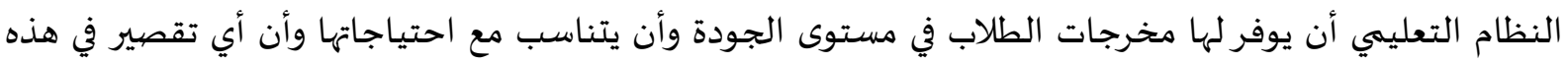

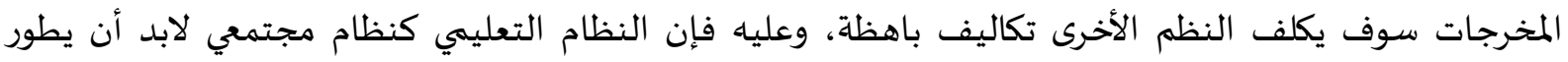

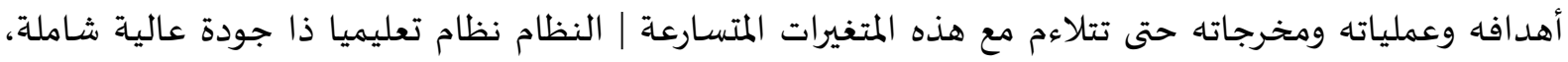

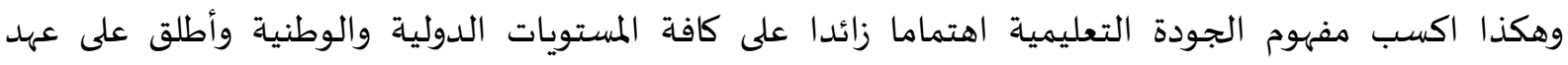
التسعينات عقد الجودة الشاملة في التعليم (الماحي، 2019). ومع أن الأدب التربوي دلّ على وفرة الدراسات التي بحثت في الجودة وإدارة الجودة الشاديات التملة، ومعاييرها في

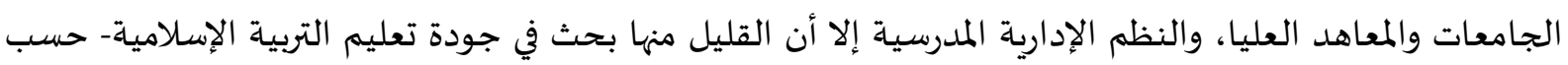

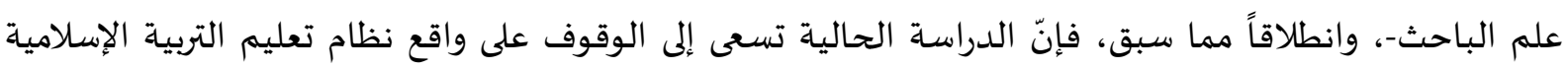

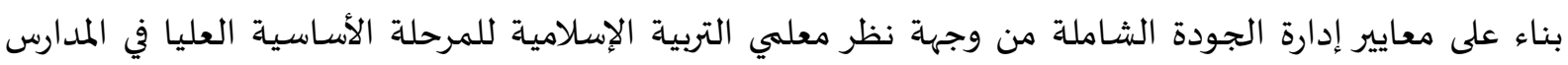
الأردنية.

مشكلة الدراسة: لقد بلغ الاهتمام بتطبيقات إدارة الجودة الشاملة في حقل التربية والتعليم في السنوات العشرة الأخيرة

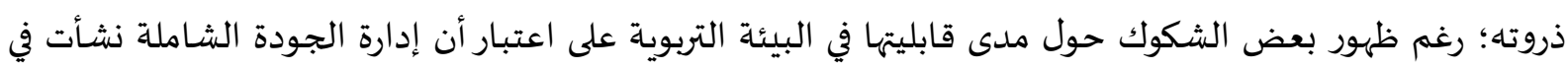

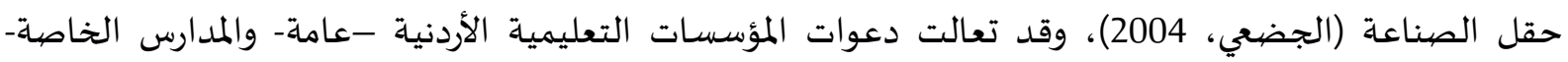

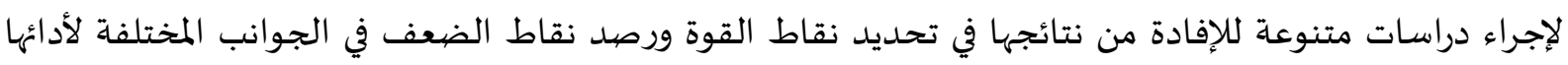
من أجل تطوير التعليم داخل المؤسسة التعليمية، ولتحقيق النقلة النوعية التي نرجو لنظام التعليم في الأردن،

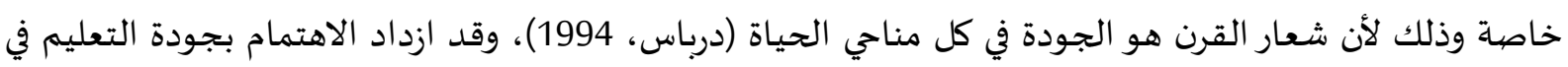

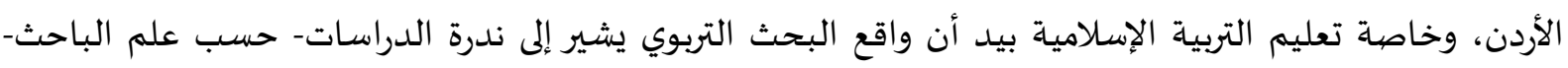

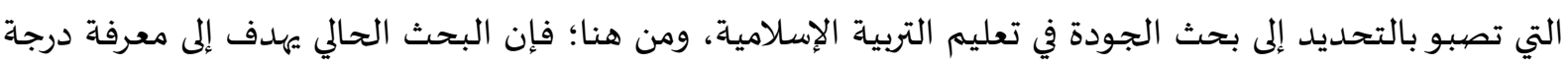

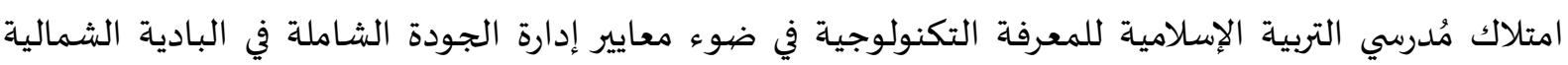
الشرقية.

أسئلة الدراسة:

تتحدد مشكلة الدراسة في الإجابة على الأسئلة الآتية: 1- ما درجة امتلاك مُدرسي التربية الإسلامية في البادية الشمالية الشرقية للمعرفة التكنولوجية في ضوء الإدية معايير إدارة الجودة الشاملة.

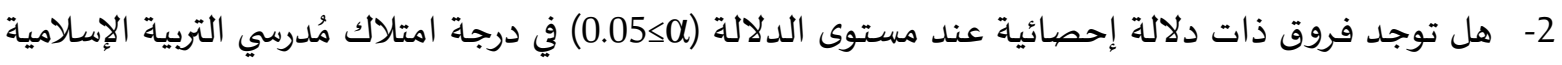

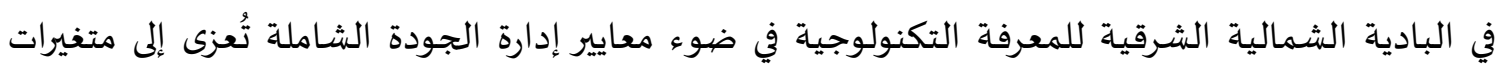

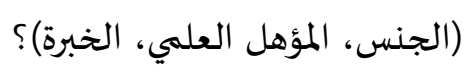


1. التعرف على درجة امتلاك مُدرسي التربية الإسلامية في البادية الشمالية الشرقية للمعرفة التكنولوجية في ضوء معايير إدارة الجودة الشاملة.

2. تحديد مدى وجود فروق عند مستوى الدلالة (0) 0.05$)$ في إجابات معلمي التربية الإسلامية للمرحلة

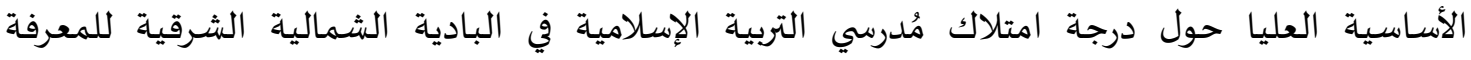

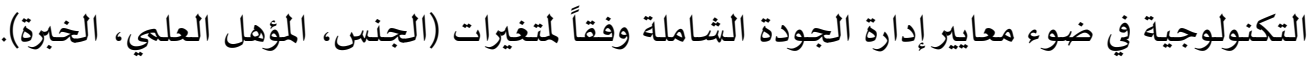

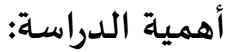

- لقد اكتسبت هذه الدراسة أهمية كبيرة -حسب علم الباحث حتى الآن والتي تحاول الوقوف على درجة امتلاك

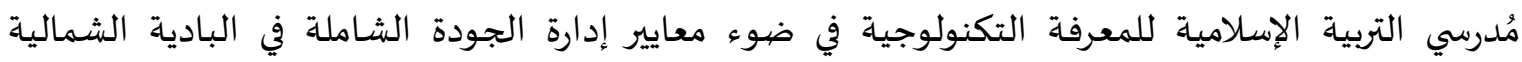

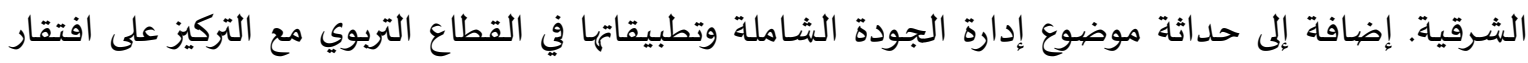

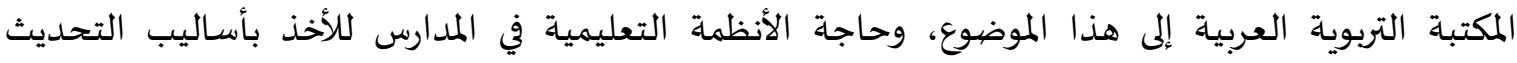

والتجديد والتطوير، وتكمن أهميتها في أهها أجريت على مُدرسي التربية الإسلامية في البادية الشمالية الشرقيه الشيكية.

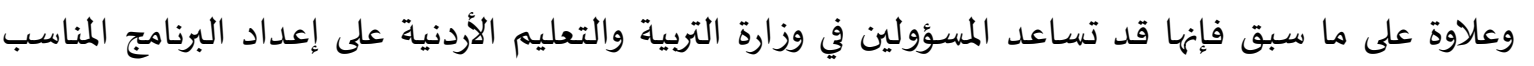

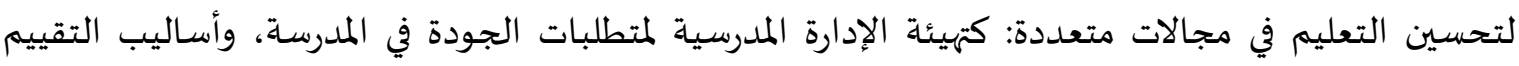

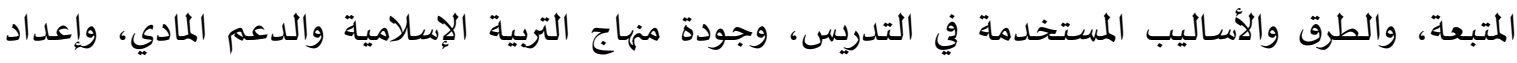

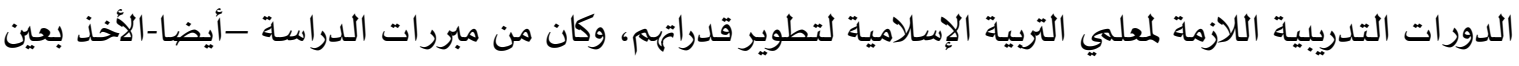

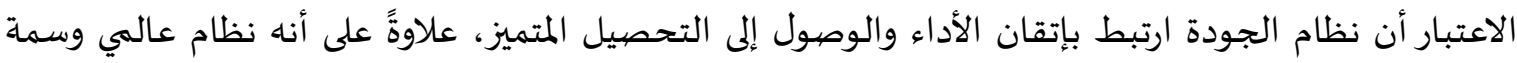

$$
\text { من سمات العصر الحديث. }
$$

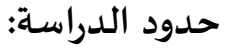

تقتصر حدود الدراسة الحالية في الآتي:

الحدود الموضوعية: درجة امتلاك مُدرسي التربية الإسلامية للمعرفة التكنولوجية في ضوء معايير الجودة الجائ

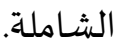

الحدود البشرية: المعلمين والمعلمات الذين يدرّسون مادة التربية الإسلامية

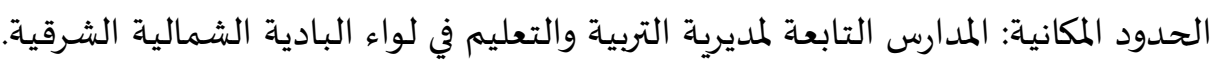

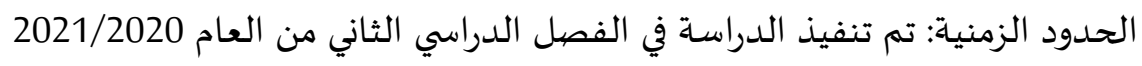

مصطلحات الدراسـة:

تمّ تعريف مصطلحات الدراسة التالية إجرائياً:

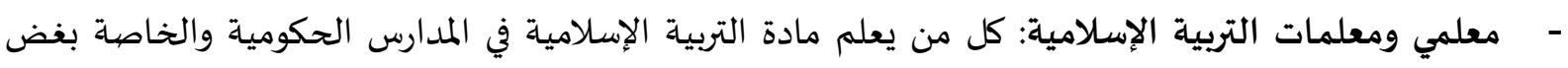

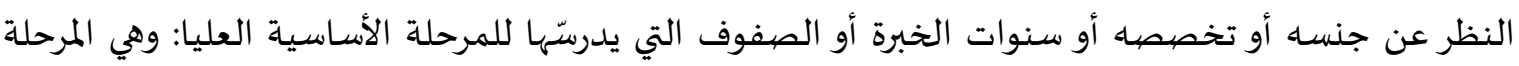
الدراسية التي تشمل الصفوف من الخامس الأساسي وحتى العاشر الأساسي.

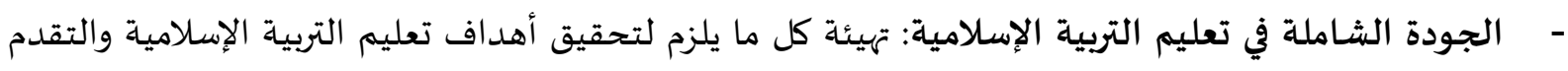

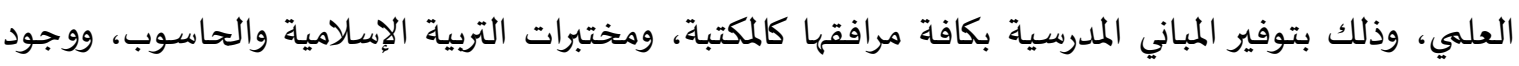

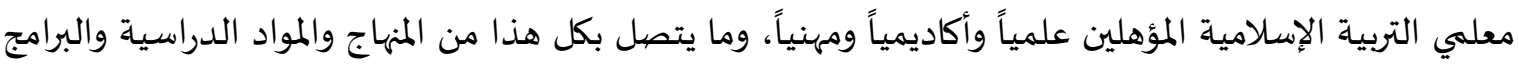
والأنشطة التعليمية والعلمية، وأساليب التقييم المناسبة، والميزانيات الكافية. 
- - المعرفة التكنولوجية: قُدرة مُدرسي التربية الإسلامية في البادية الشمالية الشرقية على تنفيذ مهارات الطباعة

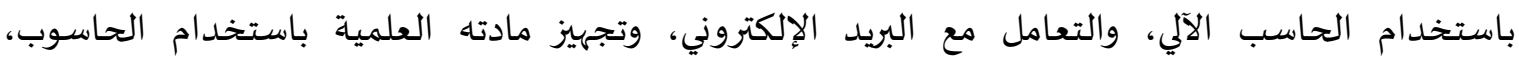

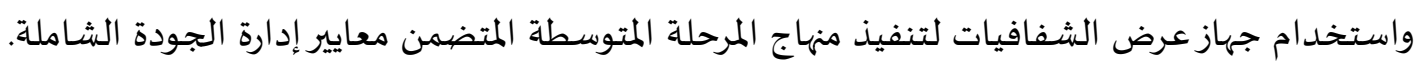

2. - 2. - الدراسـات السابقة.

قام الباحث بمراجعة مصادر المعلومات وقواعد البيانات المتوفرة بالعربية، والإنجليزية ومن هذه الدراسات

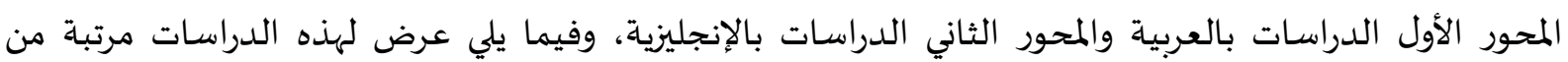
الأحدث إلى الأقدم

دراسات سابقة بالعربية:

- دراسة عبد الهادي (2020) هدفت الدراسة الحالية إلى الكشف عن مدى توافر معايير الجودة الشاملة في

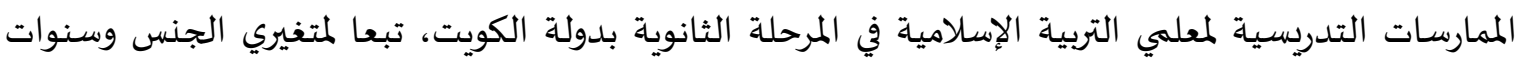
الخبرة الوظيفية، ولتحقيق غرض الدراسة تم تصميم استبانة بحثية تكونت في صورتها الهائية من (30) بنداً،

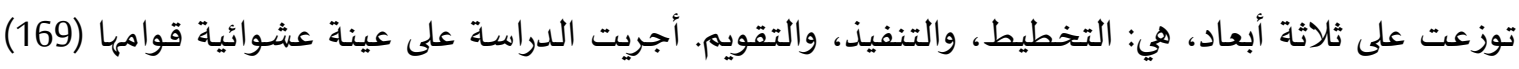

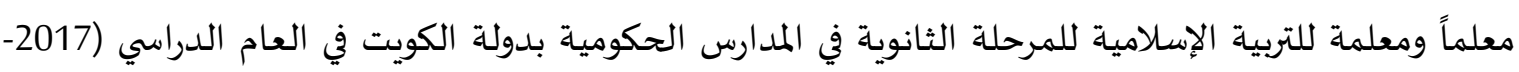

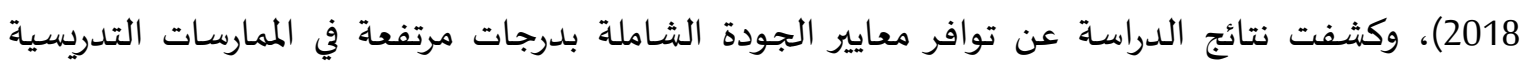

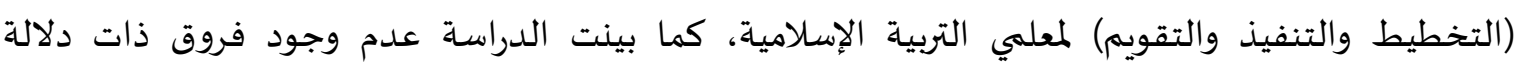

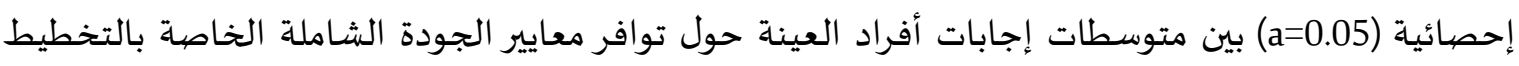

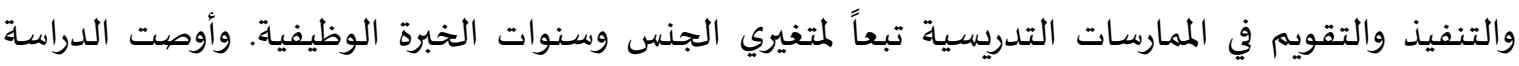

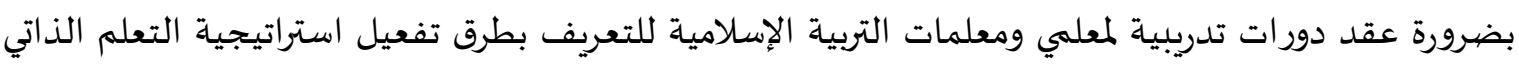
وفق معايير الجودة الشاملة، وتشجيع معلمي ومعلمات التربية الإسلامية على توظيف الوسائل التعليمية التكنولوجية على تدريس مادة التربية الإسلامية لتحقيق معايير الجودة الشاملة.

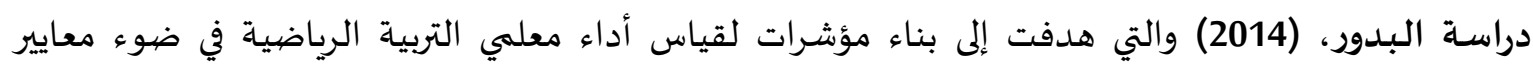

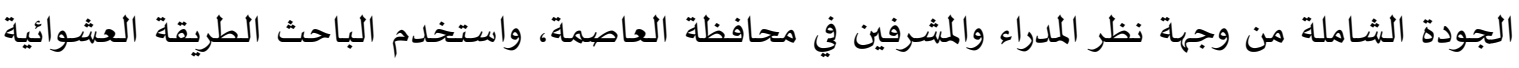

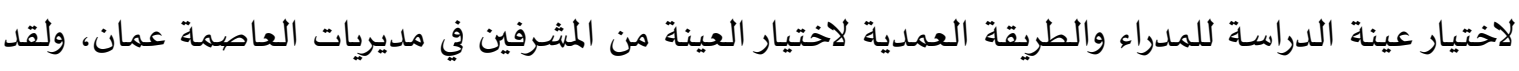

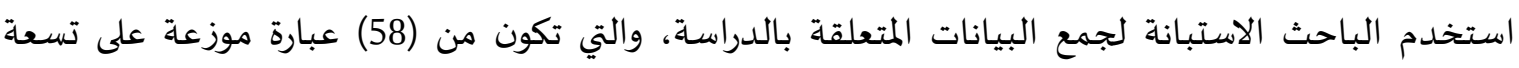

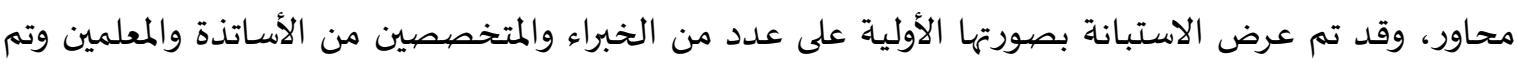

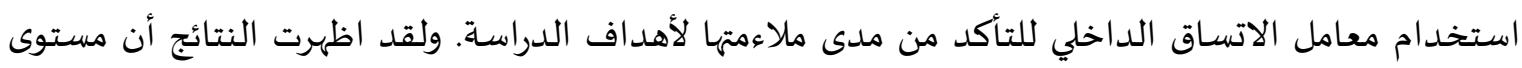

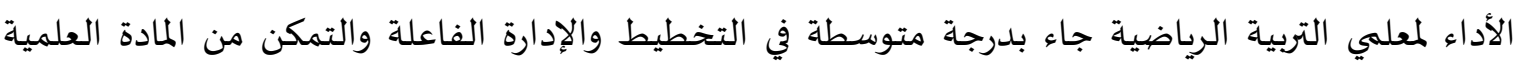

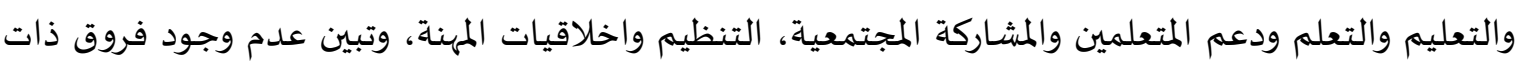

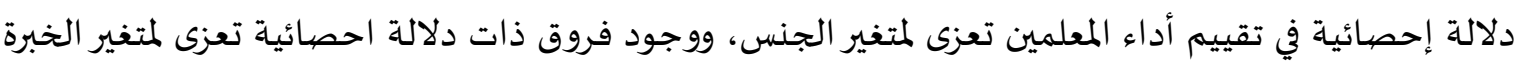

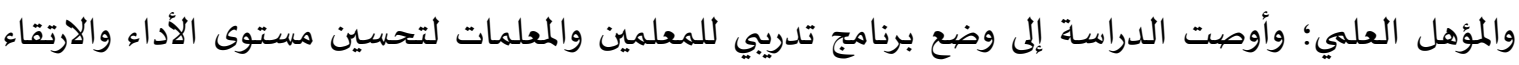
وكذلك تصميم ورشات عمل ما بين المدراء والمشرفين لاستخدام أداة التقييم المقترحة.

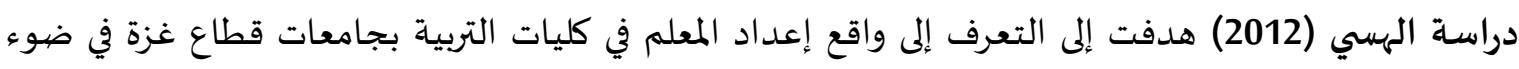
معايير الجودة الشاملة. وتم تطبيق أداة الدراسة على عينة طبقية عشوائية من الطلبة الخريجين (طلبة المستوى 
الرابع) في كليات التربية في الجامعات (الأزهر، الإسلامية، الأقصى) حيث بلغ حجم العينة (546) طالباً وطالبة

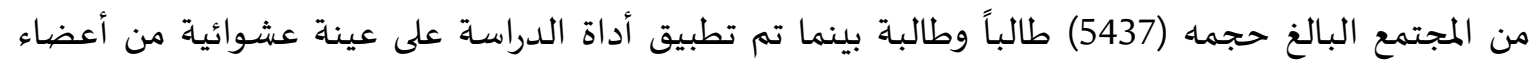

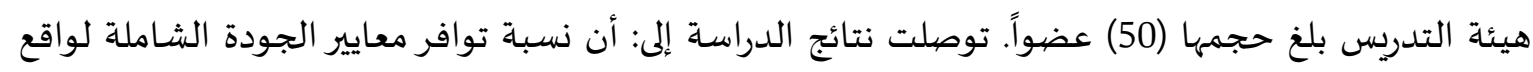

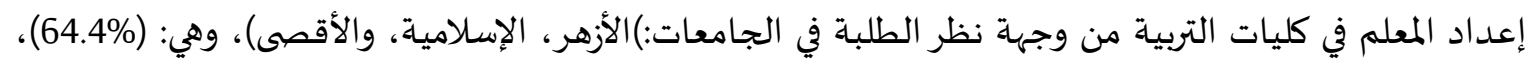
(65.2\%)، (66.2\%) على الترتيب بنسبة (64.6\%) فيما كشفت نتائج الدراسة أن نسبة توافر معايير الجودة

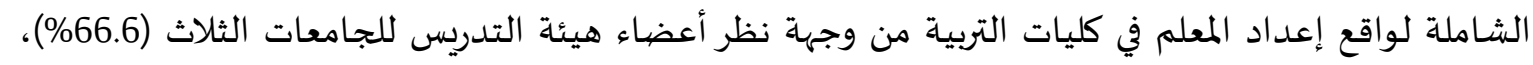

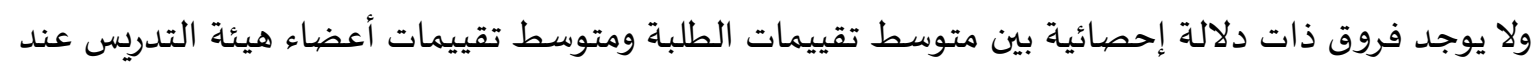
مستوى دلالة (0.05). دراسة العساف والصرايرة (2012) هدفت إلى تقصي مدى وعي المدرسين بمفهوم التعلم الإلكتروني، وواقع

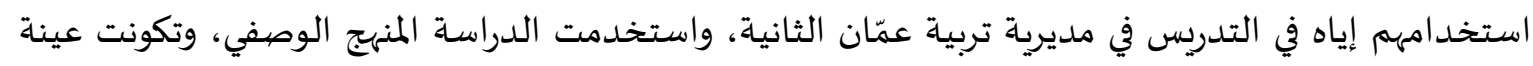

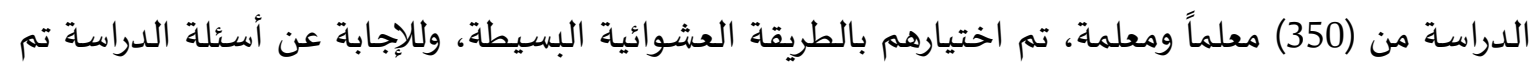

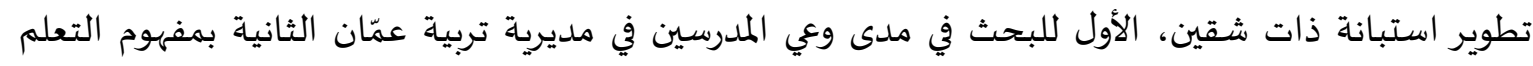

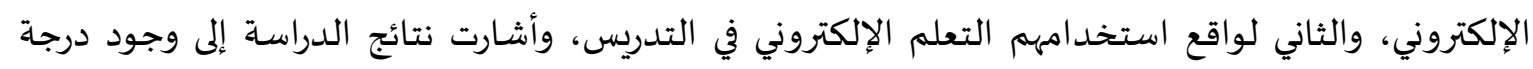

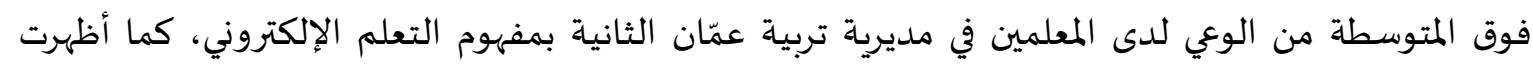
الدراسة وجود درجة متوسطة في استخدام الحاسوب، واستخدام الشبكات، واستخدام الانترنت في عملية التعلم الإلكتروني لدى المعلمين.

- أبو قاعـود (2011) والتي هدفت إلى الكشف عن درجة تطبيق المشرفين التربويين لمبادئ إدارة الجودة الشاملة

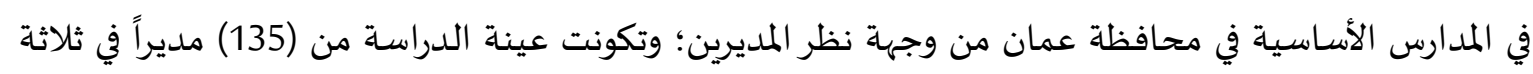

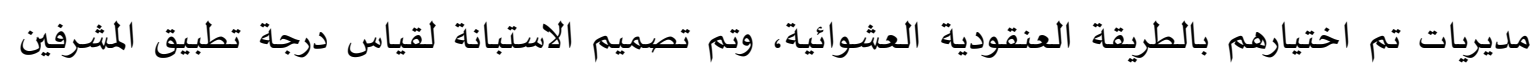

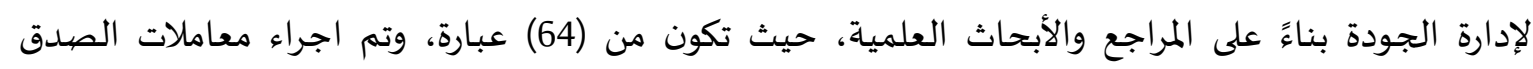

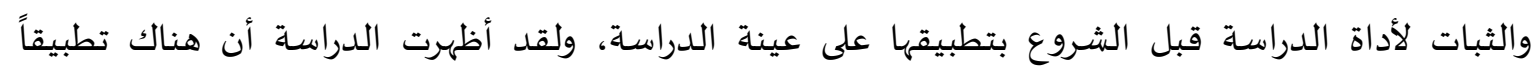

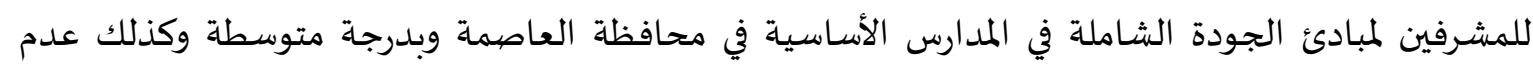

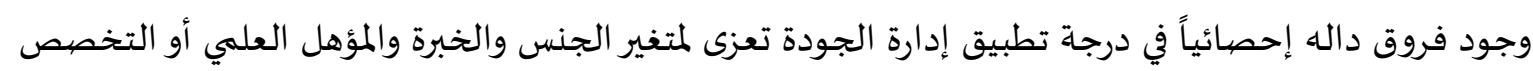

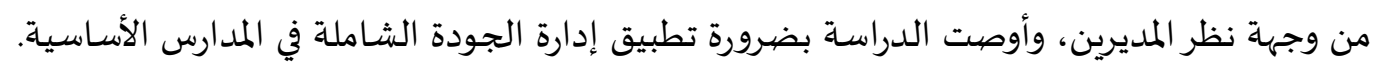

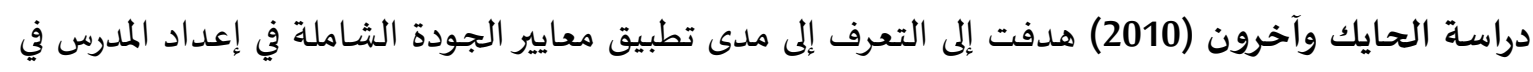

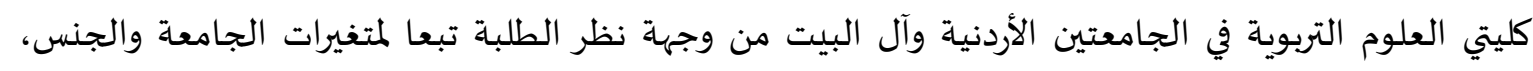

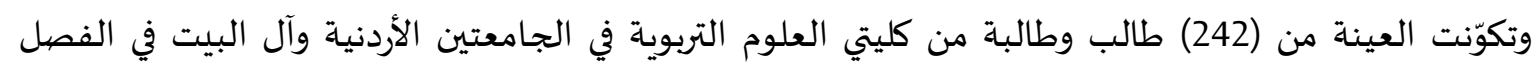

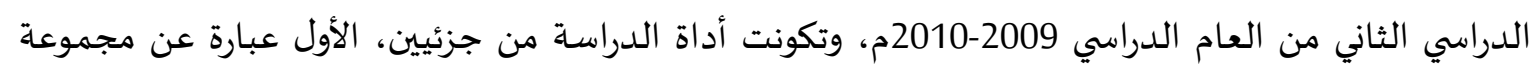

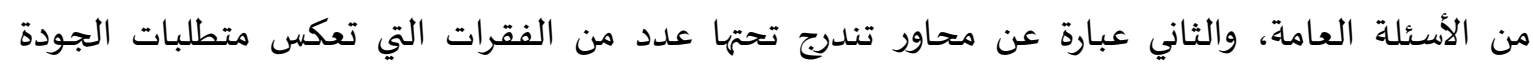

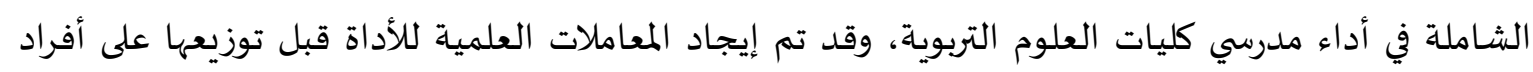

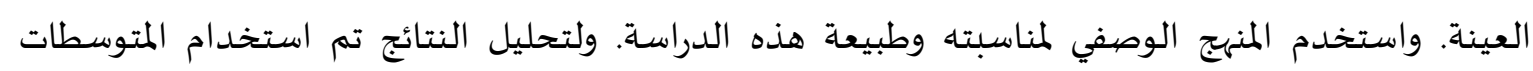

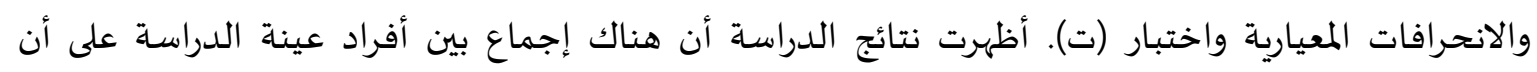

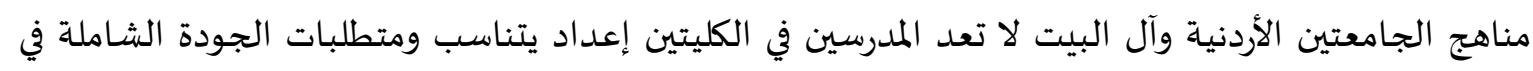
الإعداد المهني، أي أن هناك قصورا واضحا في تحقيق متطلبات الجودة الشاملة في إعداد المدرسين. ودلت النتائج 
أيضا على أتفاق الطلبة وعدم وجود فروق استجاباتهم في الكليتين، كما دلت النتائج على عدم وجود فروق ذات دلالة إحصائية تعزى لمتغير الجنس. دراسة الطراونه، (2010) والتي هدفت إلى التعرف على درجة تطبيق معايير إدارة الجودة الشاملة في المدارس

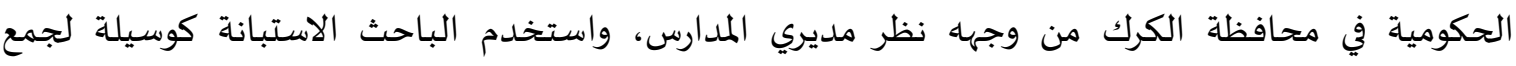

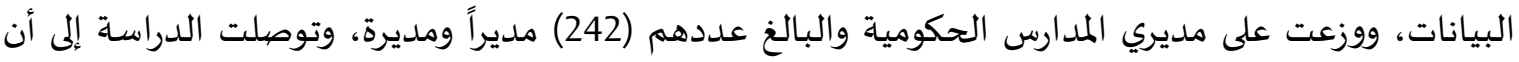

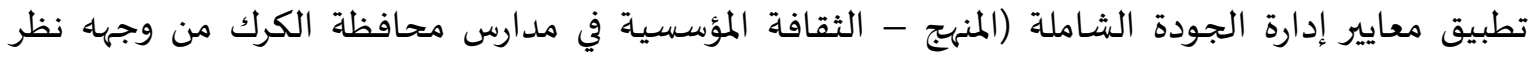

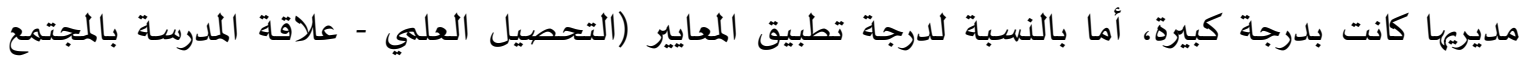

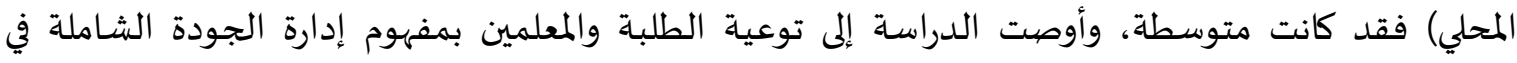
التعليم المدرسي ليشارك الجميع في تحقيق التحسين المستمر في العملية التربوية.

ب- باسات بالإنجليزية: دراسـة كاريا (2016، Karia) دراسة بعنوان" أثر تطبيق مفهوم الجودة التدريب والتعليم، بناء الفريق، التمكين الإداري، التحسين والتطوير المستمر) في بعض المتغيرات المتعلقة بالعمل (الرضا الوظيفي، والولاء التنظيمي). هدفت إلى التعرف على أثر تطبيق مفهوم الجودة (التدريب والتعليم، بناء الفريق، التمكين الإداري، التحسين

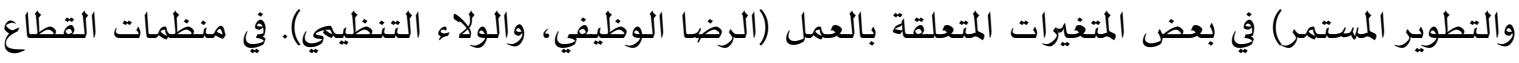
العام والخاص في ماليزيا، وشملت الدراسة (200) موظفا، وتوصلت الدراسة إلى وجود أثر ايجابي لتطبيق مبادئ

إدارة الجودة الشاملة في (الرضا الوظيفي، والولاء التنظيمي). دراسة جافريئيل ورومر (2012، Gavriel and Romar): وقد هدفت هذه وأدهاء الدراسة توضيح كيفية تطبيق إدارة الجودة الشاملة في التعليم العالي، وذلك من خلال تحديد وتحليل الأدوار المزدوجة للطلاب والمعلمين. كما

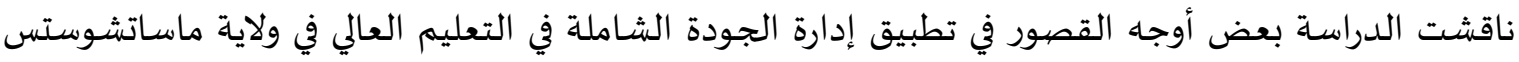

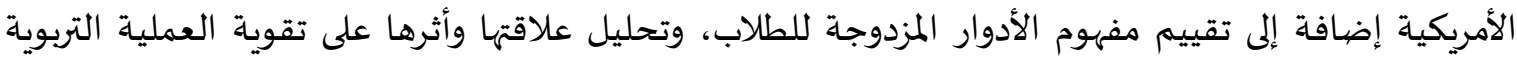

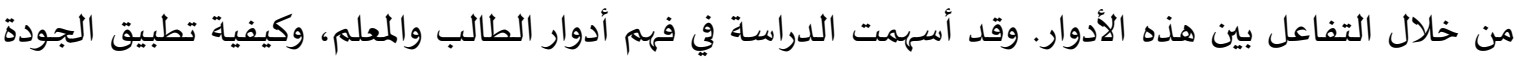

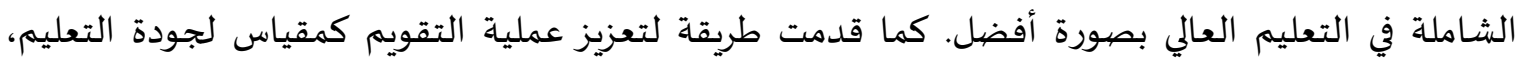
وتقديم إجراءات يمكن أن تقوي دافعية للطلاب للبحث عن المعرفة.

التعقيب على الدراسات السابقة: في ضوء عرض الدراسات السابقة استفاد الباحث من تلك الجهود في عدة مجالات يمكن إجمالها فيما يلي: هدفت الدراسات السابقة إلى تقدير للاحتياجات التدريبية للمتدربين، والكفايات التكنولوجية التي يمكن استخداهيا لتطوير وتحسين كفايات المعلمين التكنولوجية والتعليمية، وتدريب المعلمين لتحسين قدرتهم على ملاحظة المؤثرات في القاعة التدرديية، والكفايات التكنولوجية، والكفايات التكنولوجية التعليمياة، وامتلاك المعلمين للكفايات

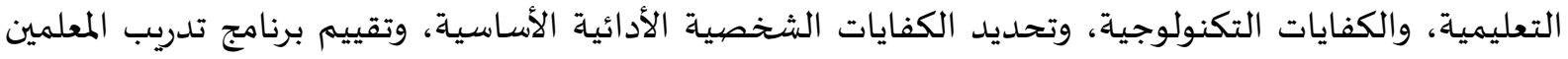

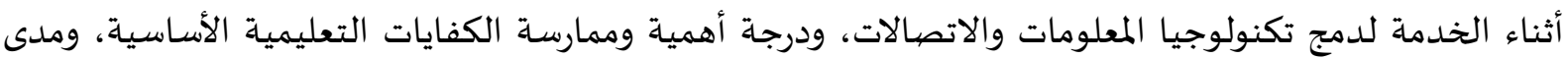

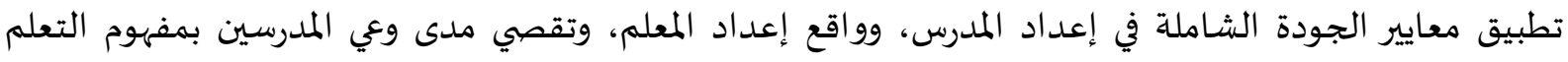

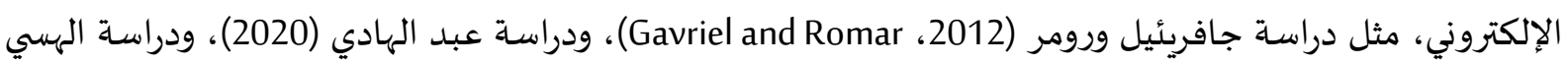

(2012)، ودراسة كاريا (2016، (Karia). 
كما يتضح لنا من العرض السابق للدراسات ذات الصلة باهتمامات الدراسة الحالية أنها تميزت بأهها تهدف

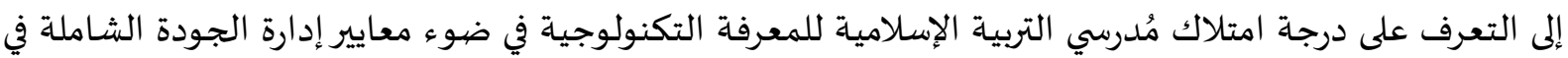

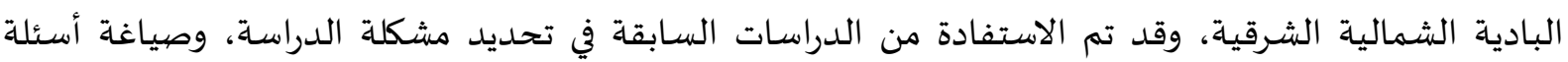
الدراسة، وتحديد مفاهيم الدراساة، وتحديد المعالجات الإحصائية، ويمكن أن تساعد نتائج هذه الدراسات في تفسير تهادير

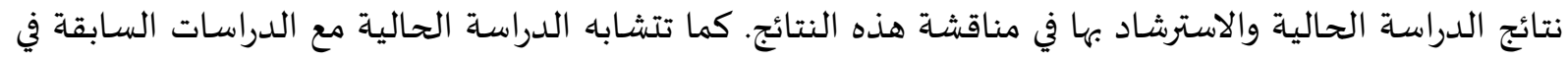

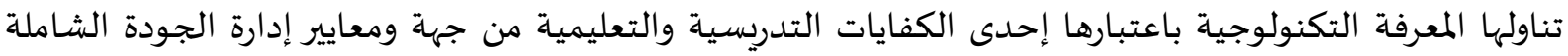

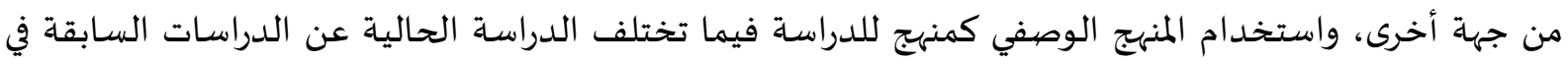

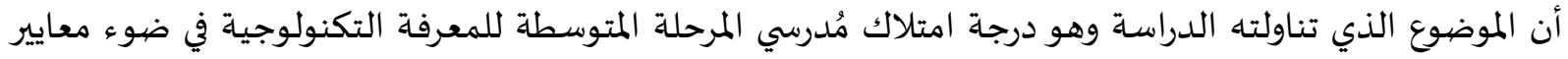
إدارة الجودة الشاملة حيث لم تتناوله الدراسات السابقة من حيث أداة البحث وراه والعينة.

3. منهجية الدراسة وإجراءاتها.

منهجية الدراسـة:

اعتمدت الدراسة المنهج الوصفي التحليلي: إذ تنتمي هذه الدراسة إلى نوع البحوث الوصفية المسحية

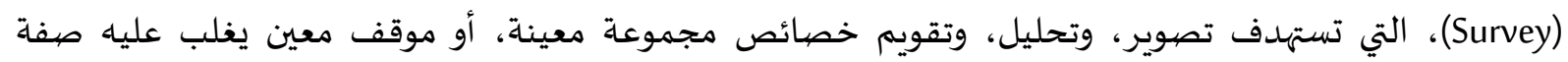

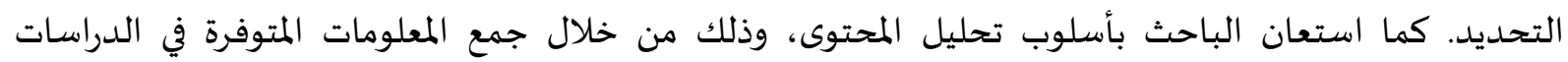

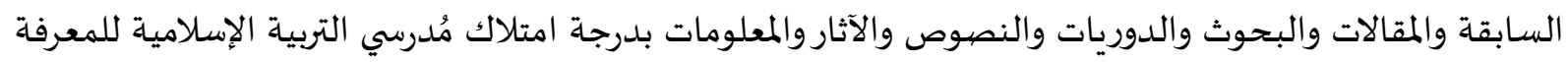

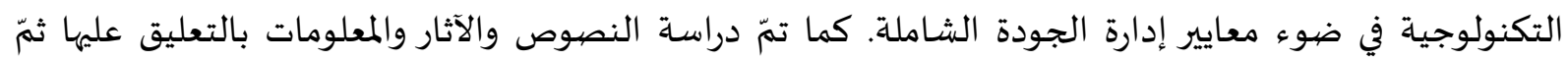

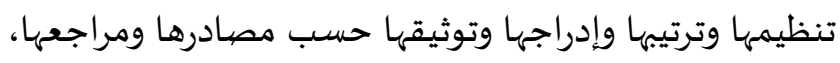

\section{مجتمع الدراسة وعينتها:}

تكوّن مجتمع الدراسة من جميع مُعلمي ومُعلمات التربية الإسلامية في المدارس التابعة لمديرية التربية

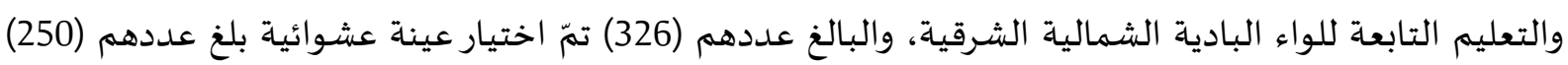

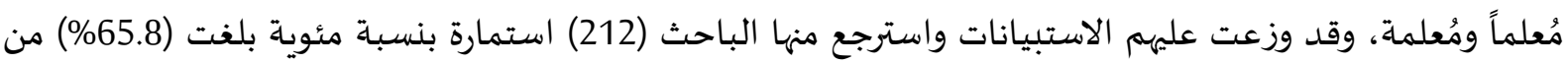

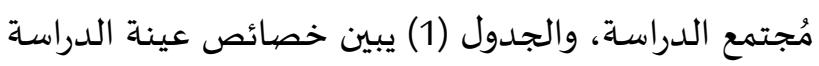
جدول (1) خصائص عينة الدراسـة بحسب متغيرات الدراسة

\begin{tabular}{|c|c|c|c|}
\hline النسبة المئوية & 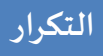 & المستوى & المتغير \\
\hline 47.6 & 101 & ذكر & \multirow{3}{*}{ الجنس } \\
\hline 52.4 & 111 & انثى انم & \\
\hline 100 & 212 & المجموع & \\
\hline 61.3 & 130 & بكالوريوس & \multirow{3}{*}{ المؤهل العلمي } \\
\hline 38.7 & 82 & بكالوريوس فأكثر & \\
\hline 100 & 212 & المجموع & \\
\hline 4.2 & 9 & أقل من خمس سنوات & \multirow{3}{*}{ الخبرة الخبرة } \\
\hline 95.8 & 203 & خمس سنوات فأكثر & \\
\hline 100 & 212 & المجموع & \\
\hline
\end{tabular}




\section{يظهر من الجدول رقم (1) ما يلي:}

1. بلغ عدد الذكور في العينة (101) بنسبة مئوية (47.6\%)، بينما بلغ عدد الإناث (111) بنسبة مئوية (52.4\%).

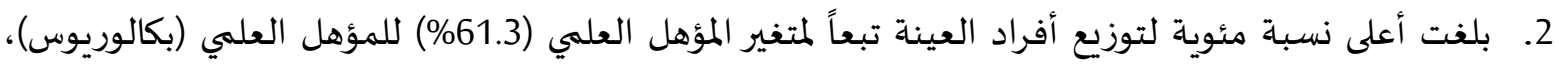
بينما بلغت أدنى نسبة مئوية (38.7\%) للمؤهل العلمي (بكالوريوس فأكثر).

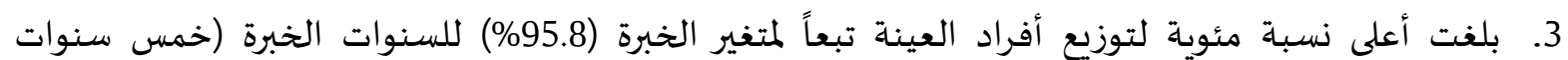

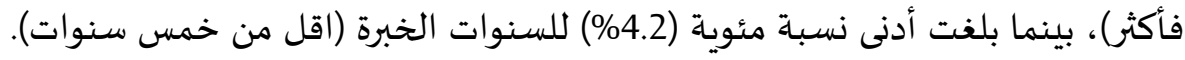

أدوات الدراسة

تم استخدام الاستبيان كوسيلة رئيسة لجمع البيانات من خلال استطلاع استجابات عينة الدراسة حول

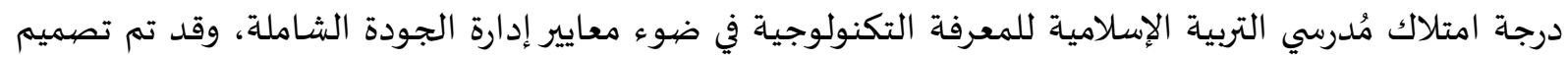
الاستبيان من خلال مراجعة الأدب المتعلق بالاتجاهات نحو إدارة الصف والكفاءة الشخصية، ومعرفة آراء ووجهات نظر المتخصصين بالمناهج وطرق التدريس وخبراء في القياس والتقويم، ومعلومات شبكة الانترنت، والخبرة الميدانيانية للباحث. تكونت الأداة من جزأين: الأول، وتشتمل على معلومات شخصية عن عينة الدراسة كالجنس والمؤهل العلمي والخبرة، والثاني: يتكون من (55) عبارة موزعة على ست مجالات، وهي (نقل ونشر المعرفة، والبيئة اللازمة لازدهار المعرفة، وصياغة الرؤية والخطة، والإدارة التعليمية، واستثمار وتوظيف المعرفة، وتكنولوجيا المعلومات) تصف كل عبارة منها درجة امتلاك مُدرسي التربية الإسلامية للمعرفة التكنولوجية في ضوء معايير إدارة الجودة الشاملة، وبنيت

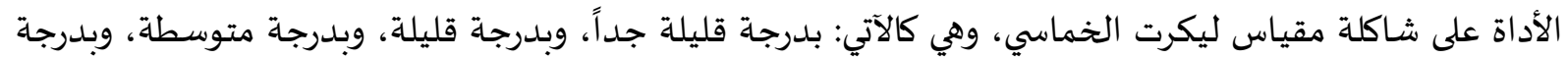

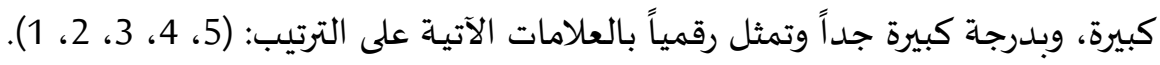

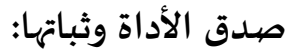

للتأكد من صددق الأداة ظاهرياً عُرضت على عدد من المتخصصين بالمناهج وطرق التدريس وخبراء في القياس

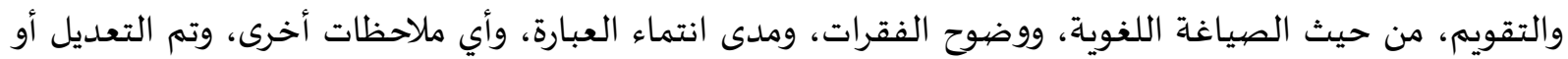

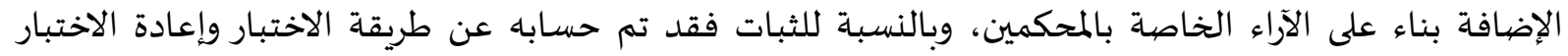
(Test-Retest) والتطبيق الثاني ثم استخراج الباحث معامل الثبات باستخدام معامل ارتباط بيرسون ( Pearson Correlation (Coefficient (0.93-0.87)، ثمّ استخرجت معاملات الارتباط لكل مجال على حدى، حيثات حيث بلغت قيمة فيمة معامل الارتباط لإدارة

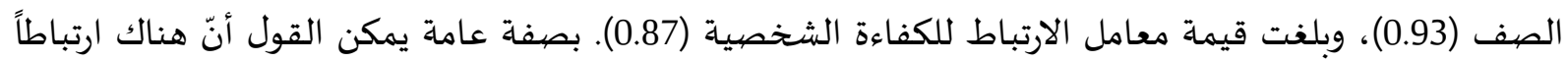

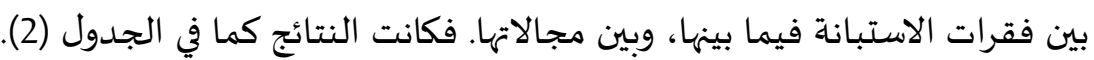

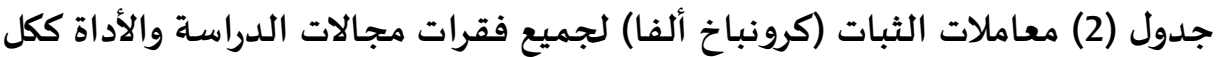

\begin{tabular}{|c|c|c|}
\hline معامل (كرونباخ ألفا) & المجال & 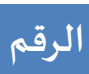 \\
\hline 0.78 & نقل ونشر المعرفة & 1 \\
\hline 0.87 & البيئة اللازمة لازدهار المعرفة & 2 \\
\hline 0.88 & صياغة الرؤية والخطة & 3 \\
\hline 0.90 & الإدارة التعليمية & 4 \\
\hline
\end{tabular}




\begin{tabular}{|c|c|c|}
\hline معامل (كرونباخ ألفا) & المجال & 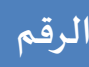 \\
\hline 0.82 & استثماروتوظيف المعرفة & 5 \\
\hline 0.72 & تكنولوجيا المعلومات & 6 \\
\hline 0.95 & \multicolumn{2}{|c|}{ الأداة ككل } \\
\hline
\end{tabular}

يظهر من جدول (2) أن قيم معاملات ثبات (كرونباخ ألفا) لمجالات الدراسة تراوحت بين (0.72-0.90)، كما

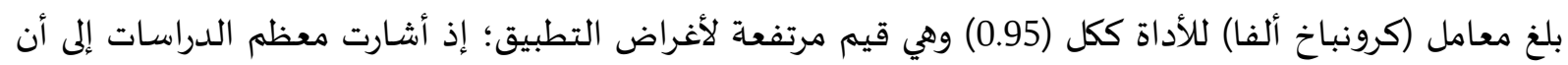
نسبة قبول معامل الثبات (0.60).

متغيرات الدراسة:

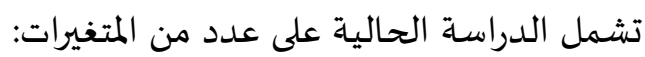

1. المتغيرات المستقلة: الجنس وله مستويان: ذكر، أنثى، والمرحلة التدريسية ولها مستويان: الأسـاسية، الثانوية،

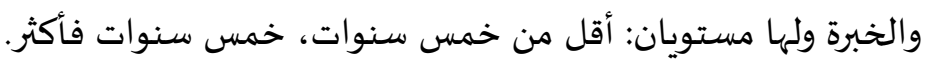

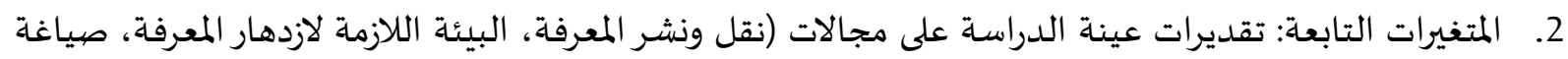

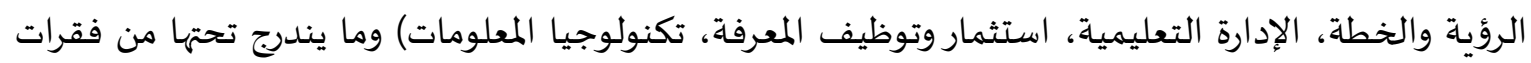

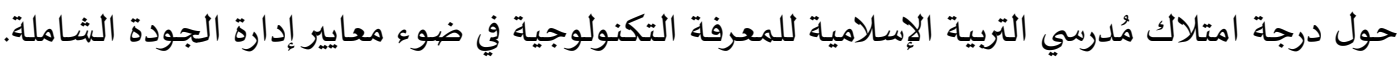

\section{4. عرض النتائج ومناقشتها.}

النتائج المتعلقة بالسؤال الأول: "ما درجة امتلاك مُدرسي التربية الإسلامية في البادية الشمالية الشرقية للمعرفة التكنولوجية في ضوء معايير إدارة الجودة الشاملة؟

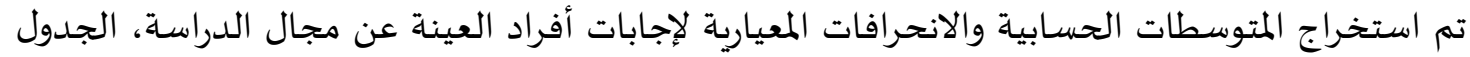
رقم (3) يوضح ذلك.

الجدول رقم (3) المتوسطات الحسابية والانحرافات المعيارية لإجابات أفراد العينة عن مجالات الدراسة وأداة ككل مرتبة تنازليا كما هو مبيّن في الجدول:

\begin{tabular}{|c|c|c|c|c|c|}
\hline التقييم & 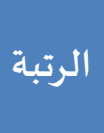 & الانحراف & المتوسط الحسابي & المجال & 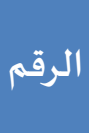 \\
\hline متوسطة & 1 & 0.18 & 3.60 & تكنولوجيا المعلومات & 6 \\
\hline متوسطة & 2 & 0.47 & 3.52 & صياغة الرؤية والخطة & 3 \\
\hline متوسطة & 3 & 0.44 & 3.45 & نقل ونشر المعرفة & 1 \\
\hline متوسطة & 4 & 0.67 & 3.22 & الإدارة التعليمية & 4 \\
\hline متوسطة & 5 & 0.49 & 3.07 & استثماروتوظيف المعرفة & 5 \\
\hline متوسطة & 6 & 0.56 & 2.91 & البيئة اللازمة لازدهار المعرفة & 2 \\
\hline متوسطة & & 0.44 & 3.30 & الأداة ككل & \\
\hline
\end{tabular}

يظهر من الجدول رقم (3) أن المتوسطات الحسابية لإجابات أفراد العينة عن مجالات الدراسة تراوحت بين

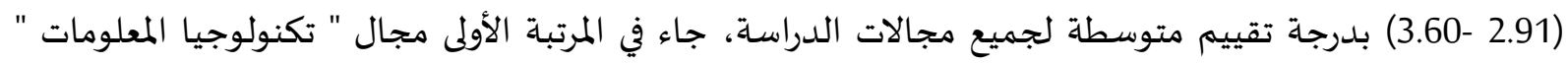

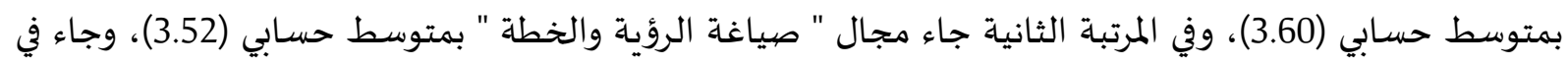


المرتبة الثالثة مجال " نقل ونشر المعرفة " بمتوسط حسابي (3.45)، وفي المرتبة الرابعة جاء مجال " الإدارة التعليمية

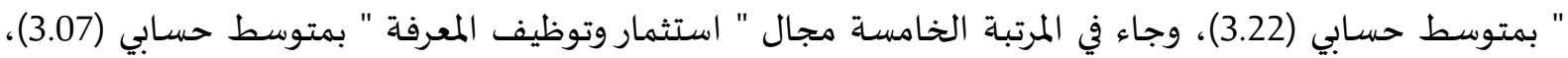

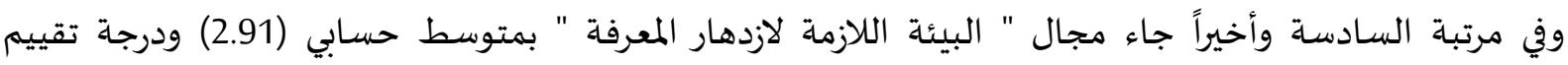

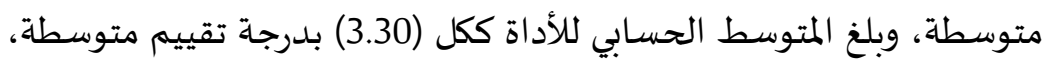

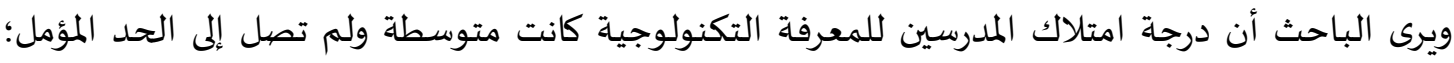
وقد يعود سبب ذلك إلى انخفاض مستوى الوعي والإدراك والمعرفة المتعلقة بمهارات المعرفة التكنولوجية في ظلل إدارة إنها

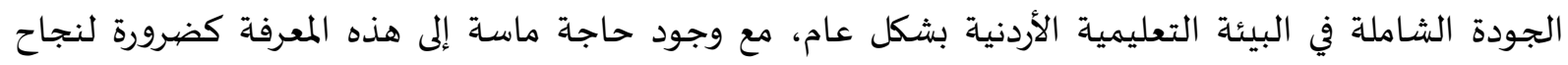

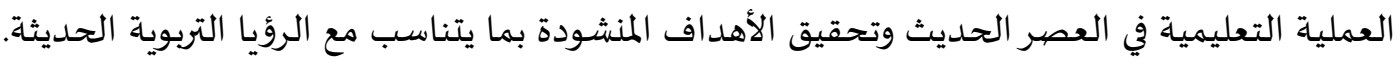

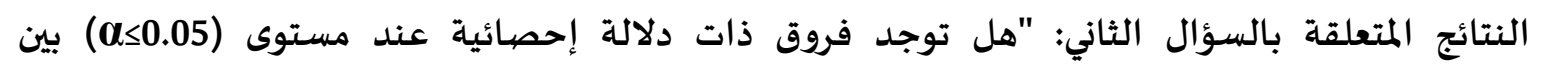

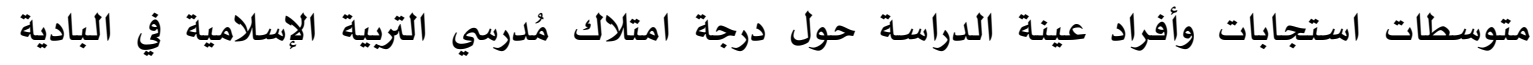

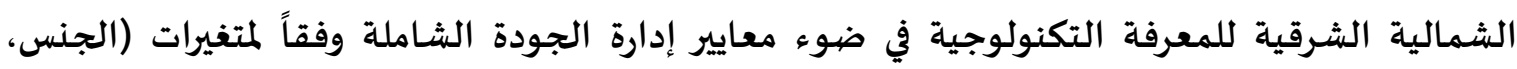

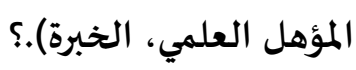

للإجابة عن هذا السؤال تم تطبيق اختبار (Independent Samples T-Test) على مجالات الدراسة والأداة

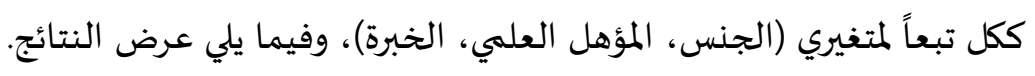

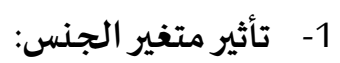

جدول (4) نتائج تطبيق اختبار (Independent Samples T-Test) على مجالات أداة والأداة ككل تبعاً لمتغير

\begin{tabular}{|c|c|c|c|c|c|c|}
\hline \multirow{2}{*}{ الإحصيائية الدلالة } & \multirow[b]{2}{*}{$\mathrm{T}$} & \multicolumn{2}{|c|}{ أنثى } & \multicolumn{2}{|c|}{ 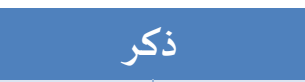 } & \multirow[b]{2}{*}{ المجال } \\
\hline & & الانحراف المعياري & المتوسط الحسابي & الانحراف المعياري & المتوسط الحسابي & \\
\hline 0.00 & $4.15-$ & 0.31 & 3.57 & 0.52 & 3.33 & نقل ونشر المعرفة \\
\hline 0.00 & $7.04-$ & 0.35 & 3.14 & 0.63 & 2.66 & البيئة اللازمة لازدهار المعرفة \\
\hline 0.00 & $10.91-$ & 0.45 & 3.79 & 0.27 & 3.23 & صياغة الرؤية والخطة \\
\hline 0.00 & $8.06-$ & 0.56 & 3.53 & 0.61 & 2.88 & الإدارة التعليمية \\
\hline 0.00 & $9.08-$ & 0.52 & 3.32 & 0.26 & 2.80 & استثماروتوظيف المعرفة \\
\hline 0.88 & 0.15 & 0.20 & 3.60 & 0.15 & 3.60 & تكنولوجيا المعلومات \\
\hline 0.00 & $10.48-$ & 0.39 & 3.92 & 0.32 & 3.40 & الأداة ككل \\
\hline
\end{tabular}

الجنس

يظهر من الجدول رقم (10) وجود فروق ذات دلالة إحصائية عند مستوى الدلالة (d>0.05) بين متوسطات

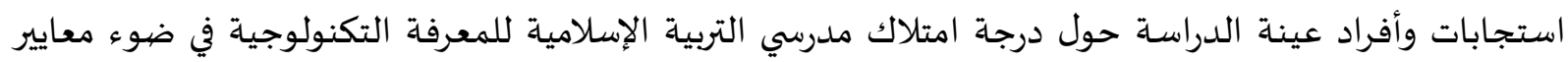

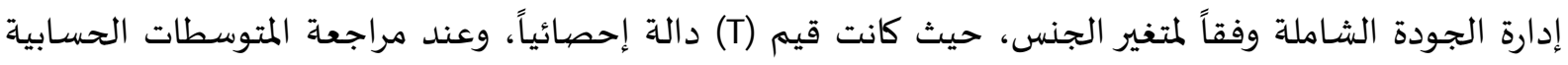

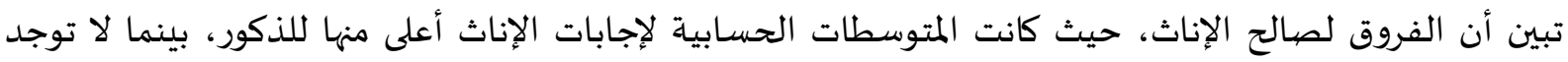

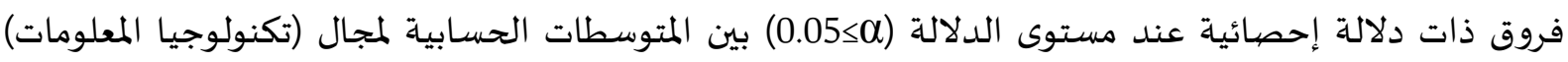

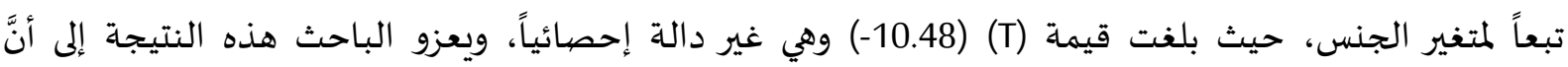

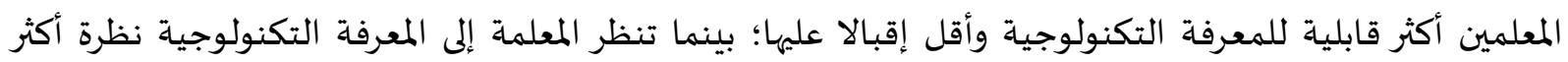


إيجابية من المعلم؛ إذ أنها عند تطبيق المعرفة التكنولوجية تستطيع القيام بالكثير من واجباتها المهنية وهي في بيتها ترعى أطفالها، واتفقت هذه النتيجة مع نتيجة دراسة البدور (2014)، ودراسة أبو قاعود (2011).

2- ت تأثير متغير المؤهل العلمي: جدول (5) نتائج تطبيق إخبار (Independent Samples T-Test) على مجالات أداة والأداة ككل تبعاً لمتغير

\begin{tabular}{|c|c|c|c|c|c|c|}
\hline \multirow{2}{*}{ الإحصائية الدلالة } & \multirow[b]{2}{*}{$\mathbf{T}$} & \multicolumn{2}{|c|}{ بكالوريوس فأكثر } & \multicolumn{2}{|c|}{ بكالوريوس } & \multirow[b]{2}{*}{ 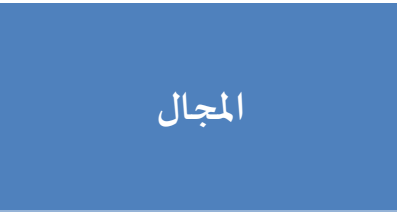 } \\
\hline & & الانحراف & المتوسط الحسابي & الانحراف & المتوسط & \\
\hline 0.27 & 1.10 & 0.34 & 3.36 & 0.45 & 3.47 & نقل ونشر المعرفة \\
\hline 0.24 & $1.18-$ & 0.31 & 3.04 & 0.58 & 2.89 & البيئة اللازمة لازدهار المعرفة \\
\hline 0.15 & 1.45 & 0.59 & 3.39 & 0.45 & 3.54 & صياغة الرؤية والخطة \\
\hline 0.63 & 0.49 & 0.77 & 3.15 & 0.66 & 3.23 & الإدارة التعليمية \\
\hline 0.50 & $0.67-$ & 0.49 & 3.14 & 0.49 & 3.07 & استثمار وتوظيف المعرفة \\
\hline 0.81 & 0.24 & 0.17 & 3.63 & 0.18 & 3.60 & تكنولوجيا المعلومات \\
\hline 0.34 & $0.97-$ & 0.49 & 3.64 & 0.44 & 3.67 & الأداة ككل \\
\hline
\end{tabular}

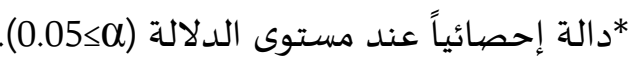

يظهر من الجدول رقم (11) عدم وجود فروق ذات دلالة إحصائية عند مستوى الدلالة (Q_0.05) بين

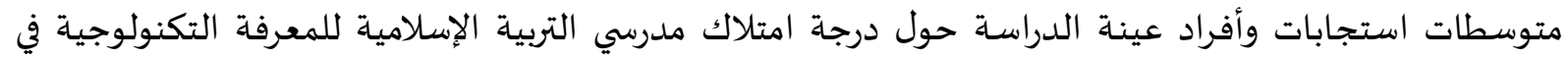

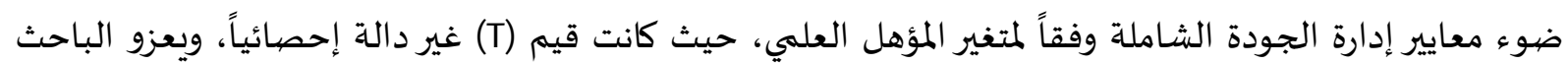

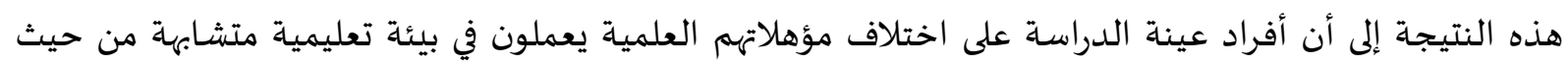

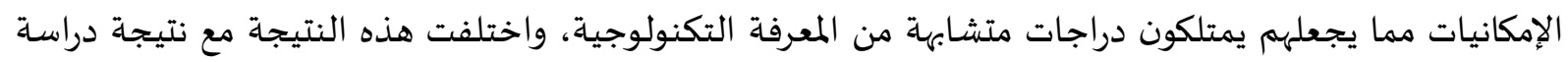
البدور (2014).

3- تأثير متغير الخبرة: جدول (6) نتائج تطبيق اختبار (Independent Samples T-Test) على مجالات أداة والأداة ككل تبعاً لمتغير

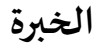

\begin{tabular}{|c|c|c|c|c|c|c|}
\hline الإحصيائية الدلالة & $\mathrm{T}$ & الات فأكثر & خمسس سد المتوسط & الاندراف سـنوات & أقل من خ المتوسط & المجال \\
\hline 0.00 & 4.31 & 0.45 & 3.38 & 0.33 & 3.65 & نقل ونشر المعرفة \\
\hline 0.00 & 3.28 & 0.61 & 2.83 & 0.29 & 3.10 & البيئة اللازمة لازدهار المعرفة \\
\hline 0.01 & $2.511-$ & 0.42 & 3.40 & 0.47 & 3.57 & صياغة الرؤية والخطة \\
\hline 0.76 & 0.31 & 0.70 & 3.21 & 0.60 & 3.24 & الإدارة التعليمية \\
\hline 0.12 & $1.551-$ & 0.50 & 3.11 & 0.47 & 2.99 & استثماروتوظيف المعرفة \\
\hline
\end{tabular}




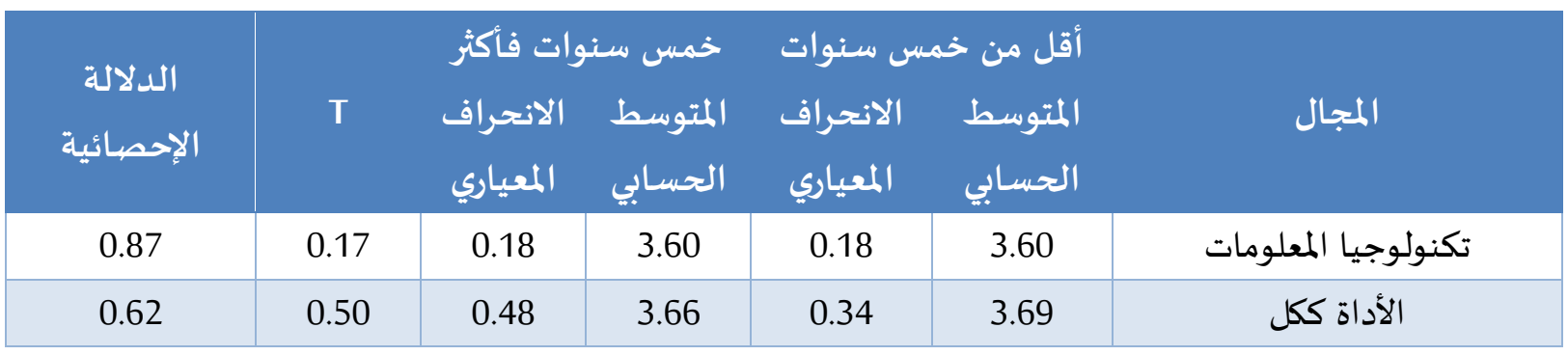

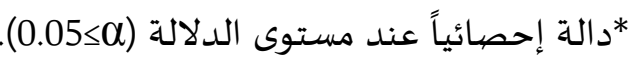

يظهر من الجدول رقم (12) وجود فروق ذات دلالة إحصائية عند مستوى الدلالة (d>0.05) بين متوسطات

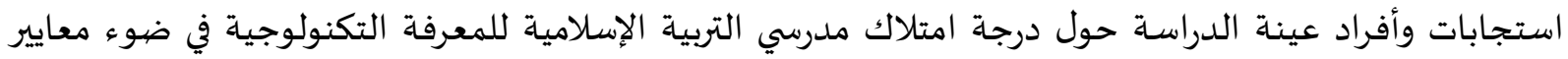
إدارة الجودة الشاملة وفقاً لمتغير الخبرة، حيث كانت قيم (T) دالة إحصائياً، وعند مراجعة المتوسطات الماتهات الحسية الحسابية تبين أن الفروق لصالح سنوات الخبرة (أقل من خمس سنوات إدوة)، حيث كانت المتوسطات الحسابية لإجابات أقل من

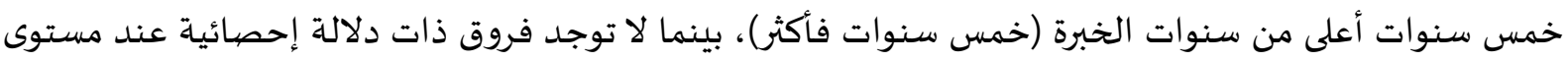

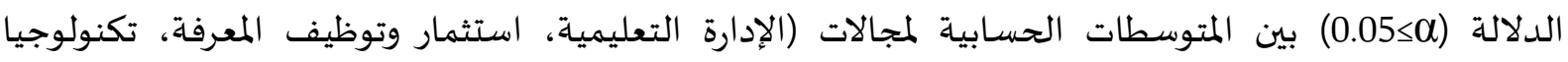

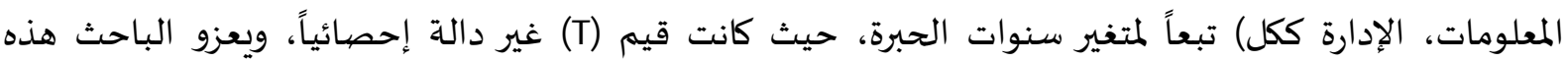
النتيجة إلى أن المدرسين الذين يمتلكون خبرات أقل قادرون على التكيف مع عناصري البيئة التعليمية وامتلاك الكفايات المتعلقة بها أكثر من غيرهم، واتفقت هذه النتيجة مع نتيجة دراسة عبد المبادين المبادي (2020).

$$
\text { التوصيات والمقترحات: }
$$

بناءً على النتائج التي توصلت إلهها الدِّراسة يوصي الباحث ويقترح ما يلي: 1. توفير الاتصال أثناء استخدام المعرفة التكنولوجية والحد من انقطاعها. 2. إعداد برامج تقوية للمعلمين وتدربههم على استخدام المعرفة التكنولوجية في المدارس. 3. ضرورة الانتقال من المعرفة التقليدية إلى المعرفة التكنولوجية. 4. ربط المؤسسات التربوية ومؤسسات التعليم كافة بشبكات المعلومات الحديثة. 5. إجراء دراسات على المعلمين لمعرفة وجهات نظرهم في المعرفة التكنولوجية.

- أبو صاع، جعفر (2019). معوقات تطبيق إدارة الجودة الشاملة في جامعة فلسطين التقنية - خضوري من

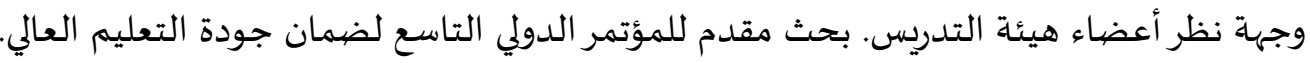

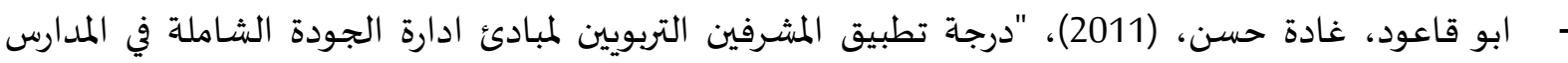

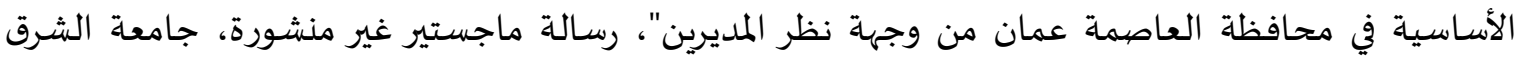
الأوسط. - البدور، وسيم عبد الرحمن اسماعيل، (2014)، بناء مؤشرات لقياس اداء معلمي التربية الرياضية في ضوء

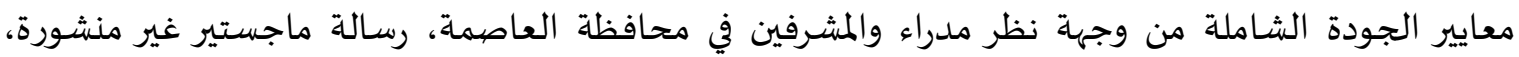
الجامعة الأردنية. 
- الحايك، صادق؛ والشوا، هلا؛ والشديفات، باسل؛ والحايك، امنه (2010)، مدى تطبيق معايير الجودة الشاملة

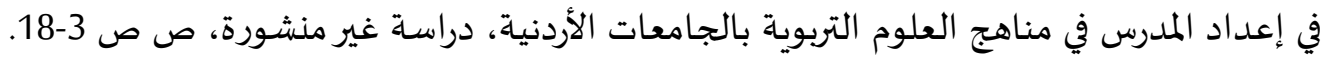

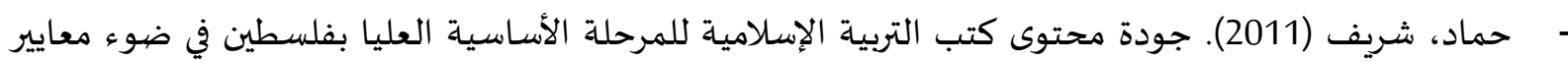

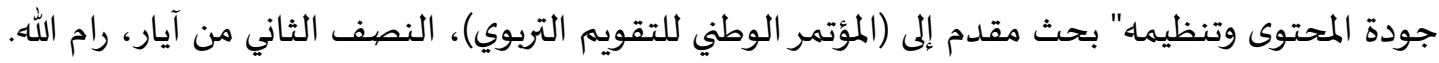

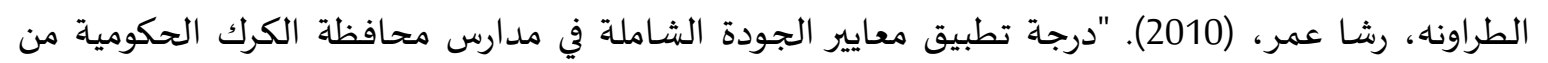
وجهة نظر مديري المدارس"، رسالة ماجستير غير منشورة، جامعاة مؤتة.

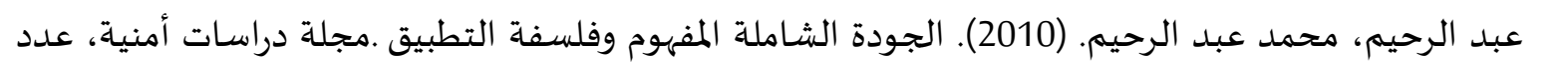

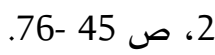

- عبد الهادي، معالي (2020). مدى توافر معايير الجودة الشاملة في الممارسات التدريسية لمعلمي التربية الإسلامية

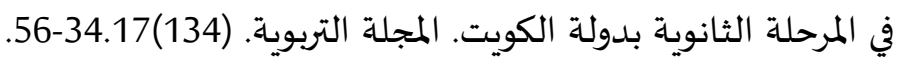

- الماحي، عواطف (2019). تقويم المدارس الخاصة مرحلة الأساس بولاية الخرطوم على ضوء معائه معايير الجودة الشاملة. (أطروحة دكتوراه غير منشورة). جامعة السودان للعلوم والتكنلوجيا: السودان.

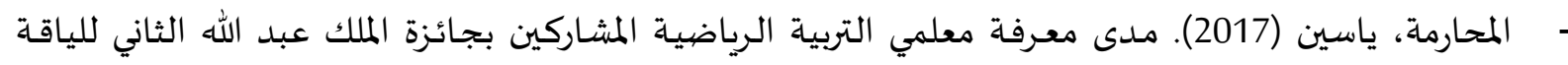
البدنيـة بمتطلبات الجودة الشاملـة من وجهاة نظر مديريهم. مجلة المنارة. (23)3. 457-490.

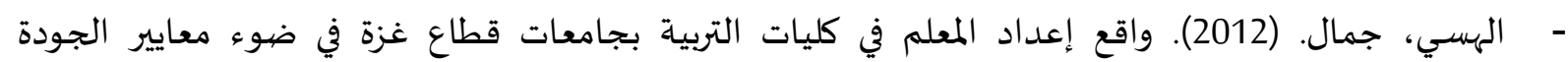

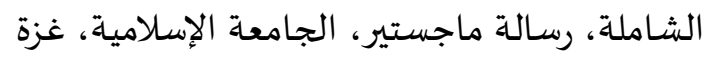

\section{ثانياً - المراجع بالإنجليزية:}

- Gavriel Meirovich and Edward J. Romar:" The difficulty in implementing TQM in higher education instruction: The duality of instructor/student roles", Quality Assurance in Education, Volume 14.issue 4.2012 \pp 423-337.

- Karia, N, \& Asaari, M. (2016) The Effects of Total Quality Management. Practices on Employees Work-Related Attitudes, The TQM Magazine, 18, 1, 30-43. 